OPEN ACCESS

Edited by: Andreas Seiler,

Swedish University of Agricultural

Sciences, Sweden

Reviewed by:

Iryna Dronova,

University of California, Berkeley,

United States

Leslie L. Bliss-Ketchum,

Portland State University

United States

${ }^{*}$ Correspondence: Anke Benten

abenten@gwdg.de

Specialty section: This article was submitted to

Urban Ecology,

a section of the journal

Frontiers in Ecology and Evolution

Received: 28 February 2017 Accepted: 22 March 2018

Published: 12 April 2018

Citation:

Benten A, Annighöfer $P$ and Vor $T$ (2018) Wildlife Warning Reflectors' Potential to Mitigate Wildlife-Vehicle Collisions - A Review on the Evaluation Methods.

Front. Ecol. Evol. 6:37. doi: $10.3389 /$ fevo.2018.00037

\section{Wildlife Warning Reflectors' Potential to Mitigate Wildlife-Vehicle Collisions-A Review on the Evaluation Methods}

\author{
Anke Benten*, Peter Annighöfer and Torsten Vor \\ Department of Silviculture and Forest Ecology of the Temperate Zones, University of Göttingen, Göttingen, Germany
}

Wildlife-vehicle collisions (WVC) produce considerable costs in road traffic due to human fatalities as well as ecological and economic losses. Multiple mitigation measures have been developed over the past decades to separate traffic and wildlife, to warn humans, or to prevent wildlife from entering roads. Among these, wildlife warning reflectors (WWR) have been frequently implemented, although their effectiveness remains a subject of discussion due to conflicting study results. Here we present a literature review on the effectiveness of WWR for $N=76$ studies, including their methodological differences, such as the type of WWR (model and color), study conditions, and study designs. We used boosted regression trees to analyse WVC-data addressed in the literature to compare WWR effectiveness depending on the study design, study conditions, effective study duration, length of the tested sections, time period of the study, data source, reflector type, and animal species. Our analyses revealed no clear evidence for the effectiveness of WWR in preventing WVC. Instead, our meta-analysis showed that most studies indicating significant effects of WWR on the occurrence of WVC may be biased due to insufficiencies in study design and/or the approach of WVC data acquisition. Our computation of log response ratios ( $L R R_{W V C}$ ) showed that only studies applying a before-after (BA) design concluded that WWR were effective. Moreover, BRT modeling revealed that only studies of $<12$ months effective study duration and $<5 \mathrm{~km}$ test site length indicated that WWR might lower WVC. Based on the vulnerability to confounding factors of WWR-study designs applied in the past, this review suggests the standardization of study conditions, including a before-after control-impact (BACl) or a cross-over study design with spatial and temporal control sections, a minimum test site length and a minimum study duration.

Keywords: animal-vehicle collisions, deer-vehicle collisions, wildlife mirrors, roadside reflectors, deer mirrors, swareflex, strieter lite, van de ree

\section{INTRODUCTION}

Since the beginning of the automobile era, wildlife-vehicle collisions (WVC) have strongly influenced the environmental impact of road traffic and have increasingly threatened both humans and wildlife (Stoner, 1925). Reliable data on economic and ecological costs is available to date for only a few European countries over the past three decades (cf. Langbein et al., 2011). For the year 
1996 alone, in Europe 500,000 collisions with ungulates, 300 human fatalities and an economic loss of ca. one billion US dollars were estimated by Bruinderink and Hazebroek (1996). Two decades later, 263,000 officially reported WVC and an economic loss of almost 0.7 billion Euros were reported for Germany alone $(\mathrm{GDV}, 2017)^{1}$. The total damage in Europe overall can therefore be assumed to be far larger than in 1996. At present, a total of $800,000 \mathrm{WVC}$ with ungulates is estimated for Germany, given that likely more than two-thirds of all collisions remain unreported, as reported for the US and Canada (Huijser and Kociolek, 2008; Snow et al., 2015; Hesse and Rea, 2016). However, WVC are not randomly distributed, but tend to accumulate in certain areas as a result of spatial and temporal factors (Gunson et al., 2011; Bíl et al., 2013). The duration of temporary WVC-hotspots is determined by diurnal and seasonal changes depending on species and climate conditions (Madsen et al., 2002; Compare et al., 2007). Furthermore, local differences in WVC-hotspots usually depend on species' habitat characteristics (Malo et al., 2004), type of road, and traffic volume (Clarke et al., 1998; van Langevelde and Jaarsma, 2009; Langbein et al., 2011; Beben, 2012). As mammals utilize landscapes at a different spatial scale than, for example, amphibians, predicting exact WVC-hotspots for these species is difficult (van Gelder, 1973; Ashley and Robinson, 1996; Madsen et al., 1998). Deervehicle collisions are the most common type of reported WVC in northern Europe (DeNicola et al., 2000; Rutberg and Naugle, 2008 ) and involve $\sim 6 \%$ of the roe deer (Capreolus capreolus) spring population (Bruinderink and Hazebroek, 1996); or up to 264,000 animals in Germany every year (GDV, 2017) ${ }^{2}$. WVC-hotspots and temporal aggregations for this species are potentially due to habitat structure (Finder et al., 1999; Nielsen et al., 2003; McShea et al., 2008), seasonality (Hubbard et al., 2000), and perhaps lunar cycles (Steiner et al., 2014; ColinoRabanal et al., 2018). Although WVC depend on both human and deer activities (Mysterud et al., 2004), deer-vehicle collisions have increased by $25 \%$ over the past decade, whereas all nondeer-vehicle collisions have decreased by $5-10 \%$ (Hothorn et al., 2015). The overall increase in WVC may therefore be due to an increase in deer population density rather than an increase in human activity or traffic intensity.

Mitigation measures (cf. Iuell et al., 2003; van der Ree et al., 2015) to reduce WVC on roads are often accompanied by high costs for construction and maintenance, including fencing, green bridges, or electric warning signs (Kruidering et al., 2005; Huijser et al., 2007a). Other, less costly measures (e.g., olfactory repellents, wildlife warning signs, speed limit reductions, or specific training to warn humans) have been shown to be ineffective in the long term, partly due to habituation (Elmeros et al., 2011; Beben, 2012). So far, only optical alarm devices, such as wildlife warning reflectors (WWR) have been occasionally reported to reduce WVC, but their effectiveness remains in question, as findings are mixed and concomitant conclusions are

\footnotetext{
${ }^{1}$ http://www.gdv.de/2016/11/wildunfaelle- erreichen-hoechststand-alle-zweiminuten-kracht-es/. Accessed 08.02.2017.

${ }^{2}$ http://www.gdv.de/2016/11/wildunfaelle-erreichen-hoechststand-alle-zweiminuten-kracht-es/. Accessed 08.02.2017.
}

highly contradictory (cf. Brieger et al., 2016). Previous reviews have surveyed outcomes on the effectiveness of WWR and have sometimes conducted meta-analyses to include national and international published studies (D'Angelo and van der Ree, 2015: $N=13$ studies; Brieger et al., 2016: $N=23$ directly available studies, $N=18$ indirectly available studies, $N=12$ newspaper articles and $N=37$ not accessible studies). However, we identified a considerable number of additional peer-reviewed studies which have not been evaluated, and which also focus on the effectiveness of WWR (Supplementary Table 1).

In this review we provide an extensive summary of research findings on the effectiveness of WWR $(N=65$ directly available studies, $N=13$ indirectly available studies); and excluded nonscientific public articles as sources. As far as we know, this is to date the most comprehensive review on the effectiveness of WWR, with almost twice as many studies than the next comprehensive review [cf. (D'Angelo and van der Ree, 2015) (N $=13$ studies), and (Brieger et al., 2016) $(N=41$ studies, 12 newspaper articles)]. In addition, we focused on methodological differences due to the variability in WWR models, such as manufacturer, reflector color, as well as study approaches, such as study designs and collision reports. This is the first study testing WWR, of which we are aware, that examines the relationship between study approaches and study results. We also aimed to identify minimal requirements for a successful study design in order to make further recommendations for effective studies on WWR efficiency. Consequently, we tested the hypotheses that: (H1) existing study results can be explained by the specifics of study designs, and (H2) a meta-analysis of previous studies identifies minimal requirements for a successful study design.

\section{FUNDAMENTALS}

\section{Wildlife Warning Reflectors}

Optical warning devices, such as WWR, are mounted along the road on guideposts oriented toward the road verge. WWR are intended to prevent wildlife from entering a road when a vehicle passes at night, its headlights reflecting off the WWR toward the road verge. The reflections from several WWR are supposed to create a "fence of light" in front of animals in close proximity to the moving vehicles. This is believed to alter the behavior of animals and interrupt their movement toward the road (e.g., Beilharz, 2017³; Schilderwerk Beutha, 2017). WWR have been distributed since the early 1960s and are now available in diverse construction types and in a variety of colors. Among the first models were the "Van de Ree" mirrors, developed in the Netherlands (McLain, 1964; Nettels, 1965), followed by the "Ruppert" reflectors (Queal, 1968). More commonly applied and tested are the models "Swareflex," developed by Swarovski in 1973 in Austria (Rudelstorfer and Schwab, 1975) and "Strieter Lite," developed by Strieter Corp. in 1994 in the United States (Barlow, 1997). Other WWR were developed by Bosch and GFT (Bosch, "WEGU," and "AWIWA" reflectors), both in Germany (Gladfelter, 1984; Ujvari et al., 1998).

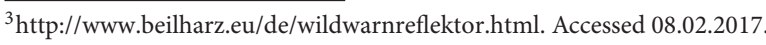




\section{Color Vision}

WWR are most commonly produced in red, but also in white or amber colors (D’Angelo et al., 2006). Whereas humans are trichromatic and perceive red as a warning signal (Goldstein, 1942; Elliot et al., 2007), most mammals, including ungulates, are dichromatic with a high density of rods (Witzel et al., 1978; Jacobs et al., 1994, 1998). Thus, ungulates have one photopigment associated with a cone mechanism for short wavelengths with a peak between 450 and $460 \mathrm{~nm}$ (S-cone), and a second photo-pigment associated with a cone mechanism 167 for middle wavelengths with a peak of $537 \mathrm{~nm}$ (M/L-cone) (e.g., Carroll et al., 2001). Therefore, red light with a wavelength of $650 \mathrm{~nm}$ exceeds the visible range of ungulates (Jacobs et al., 1994; Yokoyama and Radlwimmer, 1998; Pürstl, 2006). Thus, recently developed WWR models have been adjusted accordingly, and are now produced in colors of shorter wavelengths, such as green and blue (e.g., Beilharz, 20174; Brieger et al., 2017a,b; Kämmerle et al., 2017; Schilderwerk Beutha, 2017).

\section{MATERIALS AND METHODS}

\section{Literature Survey and Study Selection}

The available literature was surveyed systematically using the online databases ISI Web of Knowledge (webofknowledge.com) and Google Scholar (scholar.google.de). The search was conducted by combining the terms ("wildlife" OR "deer" OR "roadside" OR “animals") AND ("reflectors" OR "mirrors") using multiple languages (Dutch, Danish, German, Norwegian, Swedish, and Spanish). We additionally tested the names of various manufacturers of WWR (cf. Supplementary Table 1). All studies (including empirical studies and reviews) were filtered for their relevance regarding the effectiveness of WWR. Subsequently, we surveyed the reference lists of relevant studies for additional older studies which had not been recorded. In total, we found 76 publications evaluating the effectiveness of WWR between 1964 and 2017 (cf. Supplementary Table 1). Twelve of these studies were not accessible, but relevant information is presented indirectly through later studies in which they were cited.

\section{Data Extraction and Data Processing}

Each study was scanned for information on the reflector, reflector color, and manufacturer. If available, the respective species was documented and classified as cervid species, marsupial species, or other. All information on study duration (length in months), study location (e.g., field, enclosure, or laboratory) as well as the number and length in road distance of test- and control sites was listed. Additionally, we captured the effective study duration, which quantifies the effective duration of a test or control period, including or precluding the use of reflectors, respectively. Furthermore, the applied study design was identified [e.g., before-after (BA), control-impact (CI), before-after controlimpact (BACI), cover/uncover $(\mathrm{C} / \mathrm{U})$, behavior, other) and, finally, the number of WVC was documented. We also collected information on the data source for counts of WVC (e.g., police,

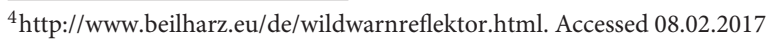

transportation administrations, research group or hunters) and the statistics used for analyzing the data (e.g., $t$-test, chisquare). To make possible an adequate comparison of observed occurrences between studies, we normalized each count of WVC to 1 year each of the effective study duration (time period of a test or control measurement) and $1 \mathrm{~km}$ of road distance $\left(\mathrm{WVC}_{\mathrm{norm}}\right.$, year ${ }^{-1} \mathrm{~km}^{-1}$ ). In total, 41 sets of WVC data with and without reflectors were considered for our analysis (Supplementary Table 1). Using $\mathrm{WVC}_{\text {norm}}$, we calculated the log response ratio (LRR) as an effect size measure of WWR-effectiveness, thus quantifying the effect of the mean outcome in the experimental group (i.e., with WWR) in comparison to the control (i.e., without WWR) as described by Hedges et al. (1999).The LRR represents a suitable metric for meta-analysis of count data, which can be easily compiled without knowledge of data variances and sample sizes of single studies (Borenstein et al., 2009).

\section{Statistical Analysis}

Statistical analyses were performed using the $\mathrm{R}$ system for statistical computing ( $\mathrm{R}$ Core Team, 2018, version 3.4.3). The response variables $\mathrm{WVC}_{\text {norm }}$ and $\mathrm{LRR}_{W V C}$ were tested for normal distribution and homoscedasticity of variances (Zuur et al., 2010; Fox, 2015). Depending on the data structure of $\mathrm{WVC}_{\text {norm, }}$ we applied parametric (paired student's $t$-test) or nonparametric statistics (Mann-Whitney U-test) to test for mean differences between each test- and control- group (WWR vs. no WWR). In the case of LRR $W V C$, we used a one-sample $t$-test to analyze whether the mean effect size was different from zero. Each time multiple comparisons were conducted we additionally implemented a Bonferroni correction. To model the significance of the study design and site conditions on the effect size of WWR, we applied a boosted regression tree (BRT) analysis. This machine learning procedure combines the regression tree approach (De'ath and Fabricius, 2000) with a boosting procedure aimed at achieving optimized model accuracy (Schapire, 2003). BRT analysis is suitable for the interpretation of ecological data as it can combine analysis of nominally and metrically-scaled data, and due to its robustness with respect to unbalanced designs, can accommodate missing data and implement interaction effects of independent variables. The interpretation of the model output is straightforward since the relative importance as well as fitted functions for each predictor variable in use can be computed (Elith et al., 2008). For this analysis we used the $\mathrm{R}$ package $\mathrm{gbm}$ in combination with BRT function $g b m . s t e p()$ as developed by Elith et al. (2008).We aimed to explain the variance in $\mathrm{LRR}_{W V C}$ and we therefore tested the importance of various possible predictors: (i) study design (BA, CI, BACI, CU); (ii) test road distance; (iii) effective study duration; (iv) data source for counts of WVC (authorities, hunters, scientists, others); (v) age of publication (1970s, '80s, '90s, 2000s, '10s); (vi) study region (North America, Europe, Australia); (vii) type of wildlife (cervids, marsupials, others); (viii) reflector type (Strieter, Swareflex, etc.); and (ix), reflector color (red, white, etc.). Since the number of observations was too small to run a BRT model testing the importance of all possible predictors simultaneously $[N=9$, reflector type, reflector color, study design, species, length of testing sites, study period, data source, effective study duration 
(i.e., times reflectors are "active") and study region], we applied a core model using study design, effective study duration and test distance as permanent predictors. To additionally select the most influential predictors from these three, we implemented a series of BRT models, in each case adding the two other possible predictors in all possible combinations. Variables were considered as predictors for the final model only when their relative importance was not below 5\%. The final model was fitted as 10 -fold replication and the results were averaged to present a mean outcome of the partially stochastic procedure.

\section{RESULTS}

\section{Behavioral, Physiological, and Spectrometric Studies on the Effectiveness of WWR}

Behavioral studies of the reactions of animals to WWR $(N=10)$ did not show any effect that would lower WVC or any reaction of animals that would decrease the risk of WVC. The reactions of different deer or marsupial species were examined mainly for Swareflex and Strieter Lite Warning Reflectors (e.g., Griffis, 1984; Zacks, 1985; D’Angelo et al., 2006; Ramp and Croft, 2006). No study found any flight behavior or increased vigilance of animals when WWR or other light sources were activated (e.g., Sheridan, 1991; Norman, 2001). If anything, D’Angelo et al. (2006) showed that deer were more likely to be involved in negative deer-vehicle interactions, i.e. that the chance of a collision between deer and approaching vehicles increased, when WWR were installed than in periods without reflectors. Moreover, spectrometric analyses of WWR showed that the reflected light intensity was infinitesimal even at short distances from the reflectors and was additionally diminished by the headlights of approaching vehicles (Sivic and Sielecki, 2001; Schulze and Polster, 2017).

\section{Methodological Differences and Results of WWR Studies}

In total, we found 76 publications evaluating the effectiveness of WWR between 1964 and 2017 (62 directly and 14 indirectly accessible, cf. Supplementary Table 1$)$. Most studies $(N=51)$ conducted analyses of WWR in the field using either a beforeafter $(N=29)$, control-impact $(N=5)$, BACI $(N=8)$, or cover/uncover $(N=10)$ study design. Of these, 39 studies provided 41 data sets which could be standardized to WVC year ${ }^{-1} \mathrm{~km}^{-1}$ with and without reflectors. Information on study duration and road length of the study sites was available in 42 and 43 studies, respectively. Behavioral analyses of wildlife and WWR were conducted in 10 studies (e.g., Ujvari et al., 1998). Additionally, four studies analyzed optical response measures of cervids with respect to WWR effectiveness, but reflectors were not tested directly in these studies (Almkvist et al., 1980; Zacks and Budde, 1983; Martschuk, 2014; Brieger et al., 2017b), thus these studies were not considered further. Other studies used spectrometric $(N=2)$, physiological $(N=1)$, or meta- $(N=$ 1) analyses to evaluate the efficacy of WWR (cf. Supplementary Table 1). Twenty studies concluded that WWR reduce WVC and 18 studies found no effect or no conclusion was provided
(Figure 1), while only 15 datasets showed a decline in WVC. Moreover, 26 data sets demonstrated (and 38 studies concluded) that there was an increase in WVC after WWR implementation.

Wildlife warning reflector models evaluated in the literature were mainly Swareflex reflectors $(N=39)$. A slightly different model (Sivic and Sielecki, 2001), the Strieter Lite WWR, was tested in 16 studies (e.g., Barlow, 1997; Riginos et al., 2015, 2018). Other reflectors evaluated were WEGU $(N=2$, e.g., Olbrich, 1984), AWIWA ( $N=2$, e.g., Voß, 2007), Bosch ( $N$ = 2, e.g., Gladfelter, 1984), Ruppert ( $N=1$, Queal, 1968), ITEK ( $N=1$, van den Berk, 2017), and Beutha reflectors $(N$ = 3, Pluntke, 2014; Brieger et al., 2017a; Kämmerle et al., 2017) (cf. Supplementary Table 1). Study duration testing the effectiveness of WWR varied from 0.75 months (Ujvari et al., 1998) to 300 months (Sielecki, 2001), depending on the study approach (e.g., behavioral observations of Ujvari et al., 1998 compared to a before-after study design of Sielecki, 2001; cf. Supplementary Table 1). In summary, the majority of authors concluded that WWR were either ineffective $(N=19)$ or even (marginally) increasing WVC with WWR $(N=26)$. Other authors resumed that an effect remained undetected $(N=7)$. In contrast, twenty studies indicated a decreasing trend in WVC with WWR (Figure 1, Supplementary Table 1). All the studies differed greatly in their methodologies (Table 1). It is notable that statistical analyses comparing WVC with and without reflectors applying a before-after design led to a significant reduction in WVC after implementation of reflectors $(p<0.05)$. Other study approaches revealed a tendency toward increases in WVC (e.g., behavioral studies, BACI, cover/uncover, Figure 1) or at least no reductions in WVC after installation of WWR (Figure 2). Only 14 publications that included information on WVC year ${ }^{-1} \mathrm{~km}^{-1}$ concluded that WWR reduce WVC (N $=13$ before-after, $N=1$ control-impact) (cf. Supplementary Table 1).

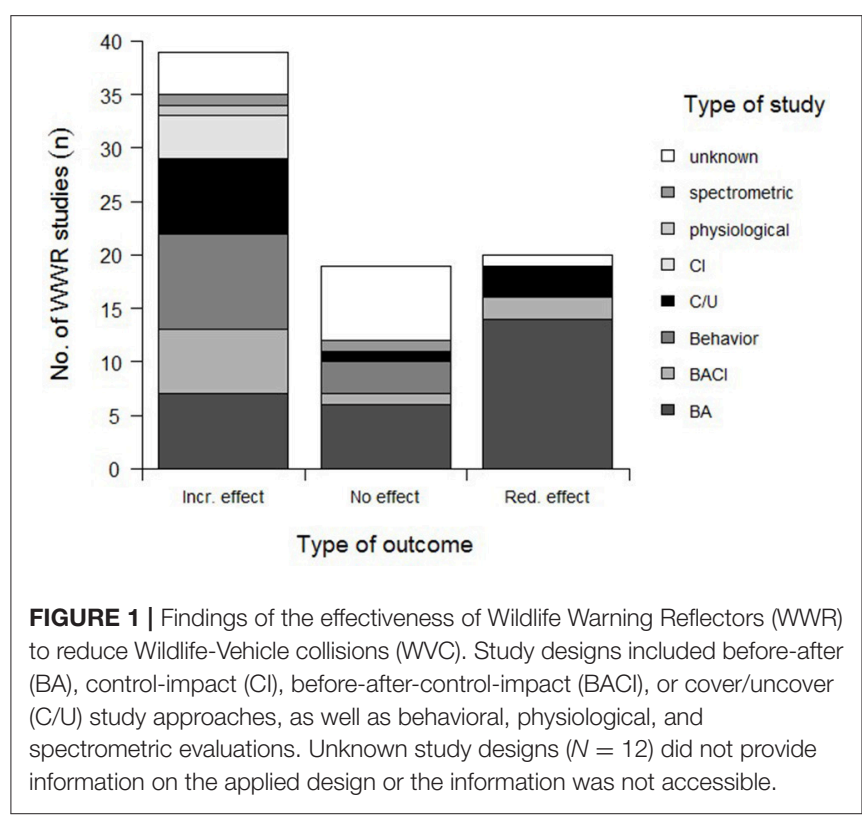


TABLE 1 | Studies evaluating the effectiveness of wildlife warning reflectors (WWR) to reduce wildlife-vehicle collisions (WVC) on roads.

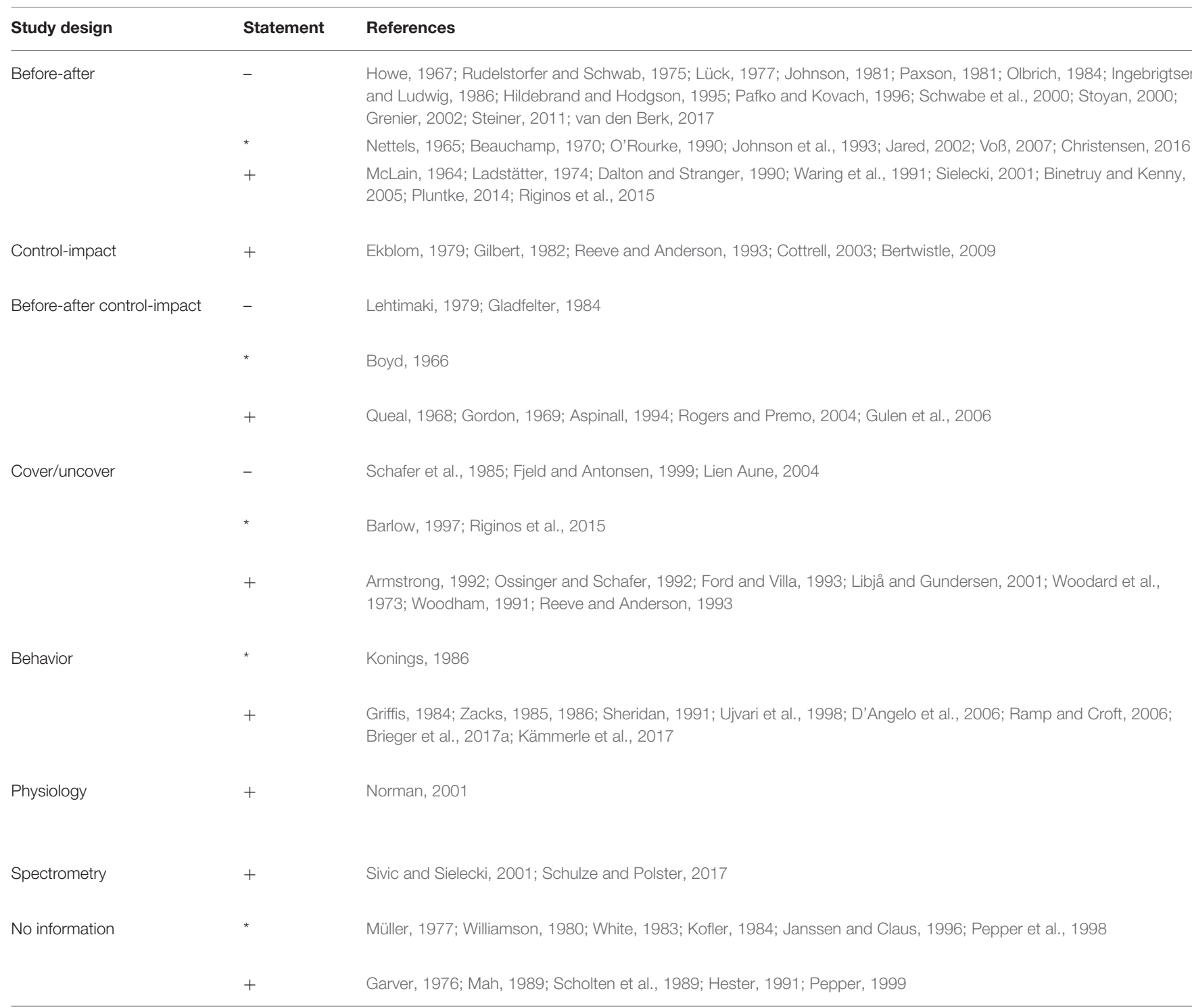

Studies are arranged by study design (i.e., before-after, control-impact, before-after control-impact, cover/uncover, behavior, physiology, spectrometry and without information on the study design). Studies were further arranged by the statement of the author on the effectiveness of the reflectors to lower WVC (-), increase WVC (+) or with no conclusion provided or found $\left({ }^{*}\right)$.

\section{Effects of Study Characteristics on the Outcome of WWR Efficiency}

Based on 41 datasets presented in 39 studies, a quantitative analysis of the effectiveness of WWR on mitigation of WVC and its dependence on study conditions was applied. With respect to BRT modeling, the pre-selection of predictors revealed insignificance of the variables study region (mean relative importance: $0.1 \%)$, reflector type (1.9\%), reflector color $(0.0 \%)$, and the considered species $(0.0 \%)$. Accordingly, the final model included five predictor variables and explained, on average, $23.2 \%$ of the variance observed in LRR ${ }_{\mathrm{WVC}}$ (Figure 3). Study design was identified as the most influential predictor (mean relative importance: $32.7 \%$ ) and the BRT revealed considerable differences between fitted values for the class before-after design in comparison to other study designs (Figure 3 ). The time of the study release as well as the testing site length of tested road segments indicated their relative importance for the accurate prediction of LRR $\mathrm{WVC}_{\mathrm{C}}$ observed $(22.1 \%$ and $23.1 \%$, respectively; Figure 3). Fitted values of LRR ${ }_{W V C}$ were generally higher using data from earlier published studies (1970-1990) and lower for more recent studies. With respect to effective testing site length, the fitted function showed a peak for the short road lengths studies (below $5 \mathrm{~km}$ ) but the explanatory power was inconclusive for distances $>\sim 15 \mathrm{~km}$ (Figure 3). Finally, the factor data source of WVC and effective study duration explained marginal degrees of the observed variance (relative importance: 14.0 and 8.2\%, 

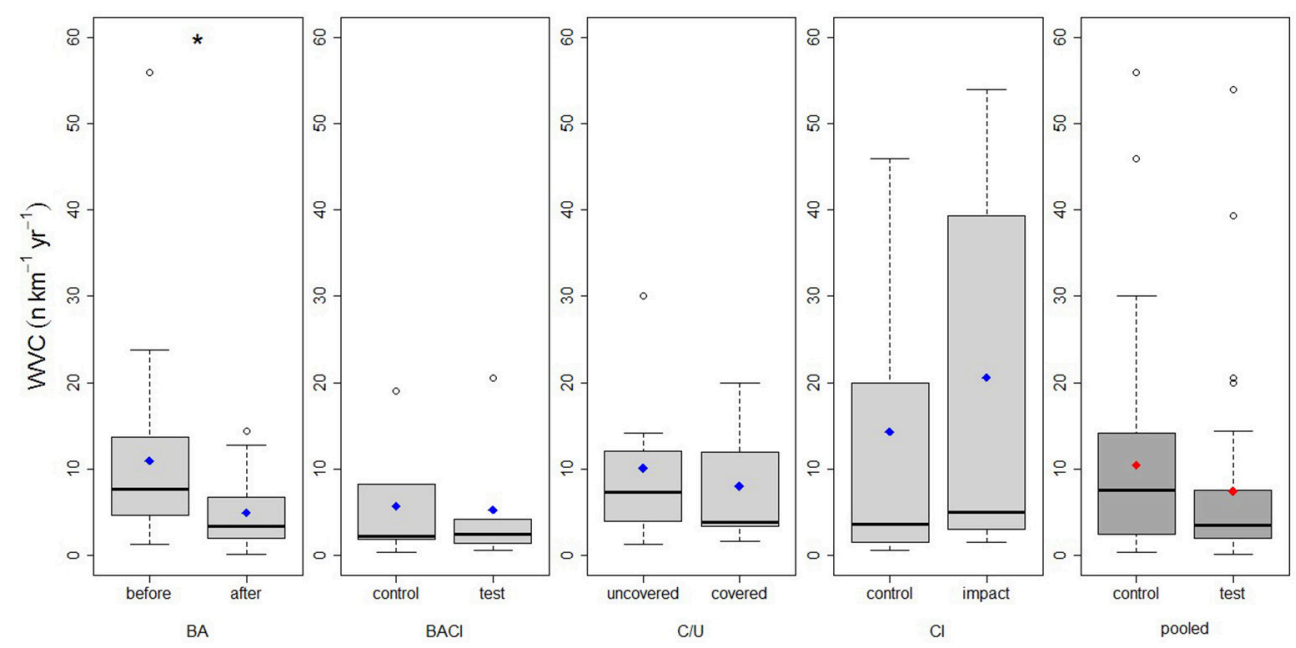

FIGURE 2 | Boxplots showing the influence of Wildlife Warning Reflectors (WWR) on Wildlife-Vehicle collisions (WVC) with respect to the study design. Data was standardized to WVC year ${ }^{-1} \mathrm{~km}^{-1}$ for both with and without reflectors. Studies performing a before-after (BA) comparison showed a significant reduction in WVC-data $(p<0.05)$. Before-after control-impact (BACl), covered/uncovered studies $(\mathrm{C} / \mathrm{U})$, as well as control-impact $(\mathrm{Cl})$ studies, did not show any significant effect of WWR on WVC-data. All standardized data comparing WVC year ${ }^{-1} \mathrm{~km}^{-1}$ for both, with and without reflectors WVC did not show any significant effect of WWR on WVC-data (pooled).

respectively). Fitted values of $L_{R R} R_{W C}$ varied slightly between datasets; for instance, those obtained from authorities, or data collected directly by scientists. The fitted function given for study duration followed the same curve as that of the road distance curve, with a high value plateau for low study durations (below 12 months) and a neutral prediction value above 20 months (Figure 3). Our statistical analyses, including BRT modeling, identified before-after study design, effective study duration $<12$ months and effective testing sites length $<5 \mathrm{~km}$ as most influential variables on the tested "effectiveness" of reflectors.

\section{DISCUSSION}

The results of both the review and the analysis of WVC-data from literature indicated that the effectiveness of WWR remains questionable and that the observed effect of WWR on WVC largely depended on other factors such as study design, effective study duration, and effective testing site length.

According to our meta-analyses the reflector model (1.9\%) or the color of the reflectors $(0.0 \%)$ did not indicate any influence on WWR. However, the risk of WVC varies during the year and the time of day, with high risks during the rutting season, as well as in the morning and first hours of the night (Hothorn et al., 2015). As ungulates, such as roe deer, prefer open areas and agricultural fields during the night (Mysterud et al., 1999a,b), the frequency of road crossings increases during darkness (Hothorn et al., 2015). Therefore, scotopic and mesopic vision play an important role in the life of ungulates with diurnal patterns (Hanggi et al., 2007), concomitant with greater rod density and better light perception in the range of blue and blue-green (Szél et al., 1996; VerCauteren and Pipas, 2003). From this perspective, the value of long-wavelength WWR is questionable and the likelihood of a reduction of WVC can be argued given the lack of animals' ability to perceive colors in these wavelengths (VerCauteren and Pipas, 2003). Modern WWR, produced and marketed in the past decade, are primarily blue (e.g., Brieger et al., 2017a; Beilharz, 20175; Kämmerle et al., 2017; Schilderwerk Beutha, 2017). However, independent studies evaluating the effectiveness of modern WWR in the field as well as the influence of blue light on feeding behavior in roe deer have not found any effect of the reflectors, either in reducing WVC directly or resulting in aversion or increased vigilance in roe deer (Brieger et al., 2017a,b; Kämmerle et al., 2017). Moreover, spectrometric analyses of WWR models have shown that the reflected light intensity is already very low at distances near the devices (Sivic and Sielecki, 2001) and reflector intensity is further overlaid by the headlights of approaching vehicles (Schulze and Polster, 2017). This applies especially to colored WWR (Sivic and Sielecki, 2001). Thus, it is doubtful that the light reflected from WWR has a sufficient intensity to elicit any reaction in animals at all.

Interestingly, some studies as well as observations by local hunters report their positive experiences with various models of WWR, including red models. A temporary reduction in WVC after installation of WWR may be explained by chance or by naturally oscillating fluctuations in population densities related, e.g., to hunting effort and food supply (Fryxell et al., 1991, 2010). Animals may also react aversively to something "new" in their environment (i.e., "novel object," cf. Forkman et al., 2007), so their reaction could be simply to the presence of the posts on which reflectors are mounted. In this case, the color of the reflector would not matter. Riginos et al. (2018) reported that carcass rates decreased by $33 \%$ when

$\overline{{ }^{5} \text { http://www.beilharz.eu/de/wildwarnreflektor.html. Accessed 08.02.2017 }}$ 

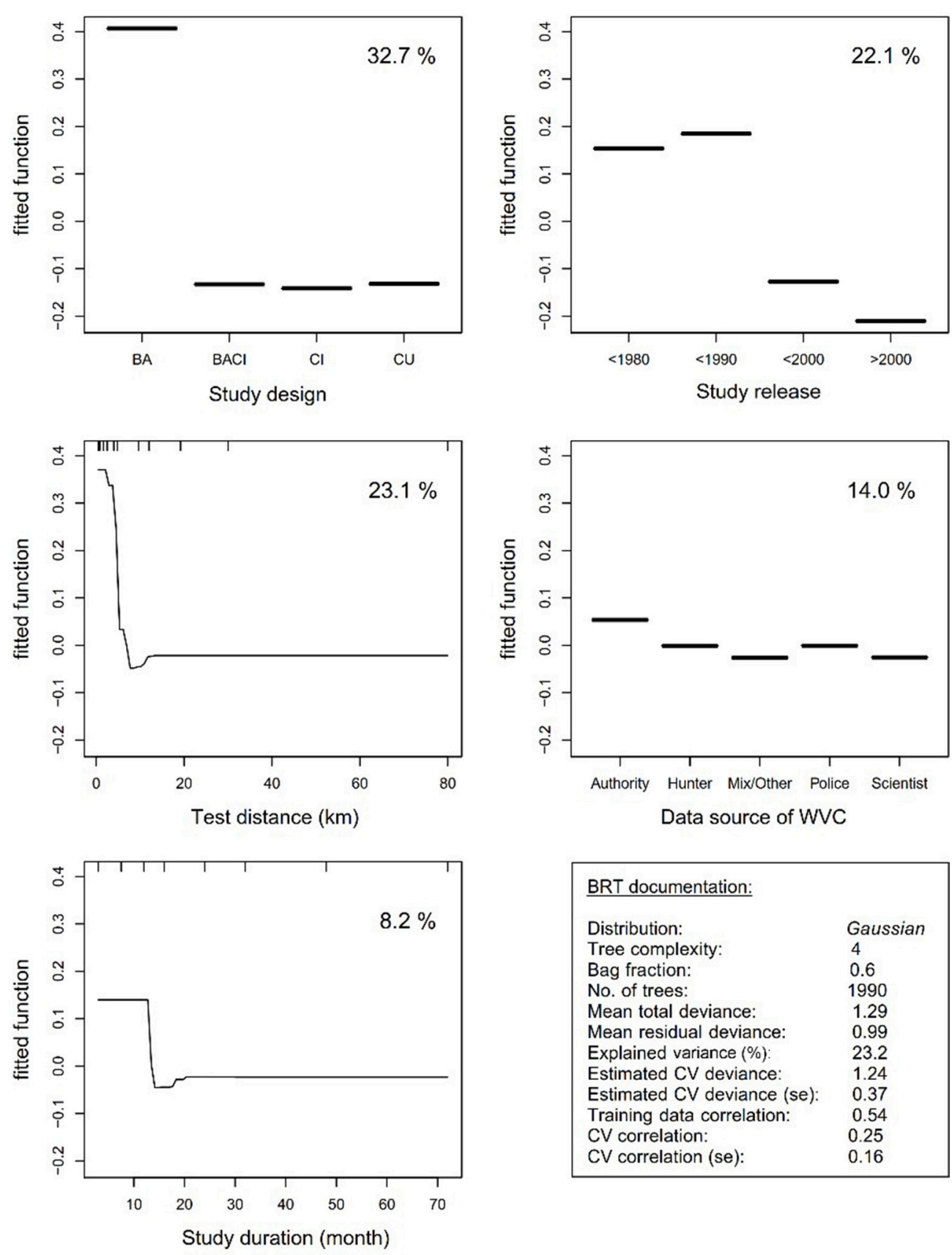

\begin{tabular}{|ll|}
\hline BRT documentation: & \\
Distribution: & Gaussian \\
Tree complexity: & 4 \\
Bag fraction: & 0.6 \\
No. of trees: & 1990 \\
Mean total deviance: & 1.29 \\
Mean residual deviance: & 0.99 \\
Explained variance (\%): & 23.2 \\
Estimated CV deviance: & 1.24 \\
Estimated CV deviance (se): & 0.37 \\
Training data correlation: & 0.54 \\
CV correlation: & 0.25 \\
CV correlation (se): & 0.16 \\
\hline
\end{tabular}

FIGURE 3 | Partial response plots of the five explanatory variables in the boosted regression tree (BRT) model including BRT documentation, such as explanatory variance of the model (23.2\%), and values indicating the relative influence of the explained variance in the BRT model, for each variable respectively. Study designs included before-after (BA), before-after control-impact (BACl), control-impact (Cl), and cover/uncover (CU) approaches. Data source was separated by authority from which data were obtained, i.e., transportation administration, road authorities), hunters, mix/other (i.e., more than one data source was used), police (i.e., WVC which were officially reported to the local police station) and scientists.

delineator posts were covered with white canvas bags compared to uncovered reflectors, but carcass rates were $32 \%$ lower with uncovered reflectors than with posts covered with black canvas bags. Thus, white canvas and reflectors might stand out more from the surrounding landscape than black. However, the animals could be expected to become habituated to the presence of these objects over time, with a resulting decline in their effectiveness. Reduction in WVC may also be due to the influence of the reflectors on the behavior of drivers rather than on the behavior of animals (Zacks, 1985), as 
the light intensity from the direct reflection to the driver is far larger than the reflection to the surroundings of the road (Schulze and Polster, 2017). An increased attention of drivers to wildlife near the road has been reported for studies testing deer-whistles, resulting in decreasing WVC (Zacks, pers. comm. 2015). However, the response of drivers to WWR has not been evaluated. It is also possible that the reflectors serve as a warning device that influences driver behavior (Rowden et al., 2008), but habituation might be expected as has been shown for wildlife warning signs (Huijser et al., 2007b).

BRT modeling showed that especially short studies, with $<12$ months of effective study duration and $<5 \mathrm{~km}$ test sites and a before-after approach, showed a decrease in WVC with WWR. Thus, we could confirm our hypotheses that (H1) study results can rather be explained by the specifics of study designs than by the presence of WWR. Additionally, we can partly confirm our second hypothesis (H2) that examination of previous studies made it possible to infer minimal requirements for a successful study design: before-after study design, effective study duration $<12$ months and effective testing sites length $<5 \mathrm{~km}$ as the most influential variables on the tested "effectiveness" of reflectors.

Before-after study designs most often detected a decrease in WVC with WWR, but it is possible that control and testing periods may not have used the same season. Activity patterns of ungulates are reflected in WVC peaks, especially during the rutting season of each species (Allen and McCullough, 1976; Lavsund and Sandegren, 1991; Hothorn et al., 2015). There could be a decrease in animals' vigilance during this period. A WVC peak during dusk and dawn, especially in the darker seasons (Steiner et al., 2014), in which high traffic volumessuch as during rush hours-coincide with an increase in the activity phase of animals. Thus, studies including all activity periods of animals are more likely to include all variables (e.g., mating season or fawning) that may influence the reactions of wildlife to oncoming vehicles. Although Brieger et al. (2016) note that a before-after study design requires at least 8 years of study to gain solid data on the effectiveness of WWR to reduce WVC, a longer study duration could be confounded by environmental changes or population fluctuations over that time period and thus affect the outcome of studies testing the effectiveness of WWR (Fryxell et al., 2010; Brieger et al., 2016).

LRR $_{W V C}$ analyses showed that only studies applying a beforeafter study design found a decrease in WVC with WWR. When studies that applied the before-after or control-impact designs were omitted, WWR did not lower WVC. Moreover, BRT models showed that the applied study design explains most of the variance $(>30 \%)$. Studying the impact of a single treatment in a paired study design usually takes the form of studying a population before and after a treatment or by studying two very similar populations or locations (Morrison et al., 2008). However, other potential factors influencing a change may complicate the interpretation of experiments, increasing the Type II error, as heterogeneity results in the confounding of experimental errors (Underwood, 1997; Morrison et al., 2008). Study designs such as before-after or control-impact designs lack the independence of different levels of single treatments and true replication (Morrison et al., 2008). Thus, although there may be no statistical problem with the study and the null hypotheses is rejected, a potential change after the implementation of a treatment cannot simply be assigned to that impact, but may be due to other factors such as weather, crop rotation, etc., (Underwood, 1997; Morrison et al., 2008). Therefore, results comparing the number of WVC before and after the implementation of WWR, as well as comparing test sites with control sites, must be treated with caution due to discontinuity in time or space. In these, BACI and cross-over study designs provide a remedy, as they have the highest inferential strength for assessing impacts on the environment (Green, 1979; Underwood and Chapman, 2003; Roedenbeck, 2007).

In addition to a number of influencing variables such as reflector model, reflector color or effective testing site length in road distance and effective study duration, the type of data collection also seems to affect the results of studies testing the effectiveness of WWR. BRT analyses showed that data sources influence the variance in the model by $15 \%$. Also, the opinion of the authors can influence study results. While Gladfelter (1984) stated that WWR reduced the number of WVC significantly, he compared test and control sites that differed strongly in WVC numbers, challenging the controlimpact approach. Moreover, WVC differed among test sites after installation of WWR; thus not all test sites showed a reduction in WVC after implementation. When his data were standardized, WVC changed only from $1.86 \mathrm{WVC}_{\text {year }}{ }^{-1} \mathrm{~km}^{-1}$ without WWR and 1.39 year $^{-1} \mathrm{~km}^{-1}$ with WWR (cf. Supplementary Table 1). Similar issues apply to the study conducted by Hildebrand and Hodgson (1995). While WVC were rather low before installation of WWR at two test $(N=1 \mathrm{WVC})$ and control sites $(N=2$ WVC), numbers increased to $3 \mathrm{WVC}$ year $^{-1}$ at the test sites and $2.75 \mathrm{WVC}$ year $^{-1}$ at the control sites after installation. Standardizing this data to the test site length, WVC actually increased from $0.38 \mathrm{WVC}$ year ${ }^{-1} \mathrm{~km}^{-1}$ without reflectors to 0.6 WVC year ${ }^{-1} \mathrm{~km}^{-1}$ with reflectors. With so few observations, a test for significance is not actually possible. However, the authors stated that they found a non-significant reduction in WVC comparing test and control sites, and concluded that WWR are effective in reducing WVC. Olbrich (1984) compared test sites that he maintained. Although WVC differed strongly among test sites after installation and no statistical test was applied, he concluded that WWR reduce WVC. In additional examples of previous study limitations, Pafko and Kovach (1996) compared data before and after installation of WWR, yet without proper information on WVC before the study and with an invalid type of data collection. However, the authors concluded that WWR effectively reduced WVC. Other studies have also failed to provide data on the numbers of WVC before installation of WWR (e.g., Nettels, 1965). For example Grenier (2002) conducted a meta-analysis including data from different highway and transportation agencies. He concluded that WWR are effective in reducing WVC, although it remains unclear which studies he considered, as studies without any effect of WWR were excluded. 


\section{CONCLUSIONS}

The effectiveness of WWR remains doubtful, due to conflicting study results and questionable study designs, especially using the before-after approach. BRT modeling indicated that only studies with $<12$ months effective study duration and $<5 \mathrm{~km}$ test sites found a decrease in WVC with WWR. Moreover, LRR $_{W V C}$ analyses showed that only studies applying a beforeafter approach concluded that WWR was effective. This design however, lacks the independence that would accrue from different levels of single treatments and true replication (Morrison et al., 2008). Thus, a potential change after the implementation of a treatment cannot simply be assigned to that impact, but to other factors as well. (Underwood, 1997; Morrison et al., 2008). Additionally, analyses of physiological abilities and spectrometric requirements in the literature provide evidence that most mammals cannot effectively perceive red light and that reflected light has insufficient intensity to elicit any reaction in animals that would lead to a decreased risk of WVC. Thus, to include as many explanatory variables, but also to exclude as many confounding factors (environmental biases) as possible, a BACI or cross-over design (Roedenbeck, 2007; Morrison et al., 2008) is advisable. Furthermore, predictive variables such as test site length, effective study duration, and data source influenced the variance observed in $L_{R R}{ }_{W V C}$. Additionally, behavioral observations of animals reacting to WWR including all activity periods, especially WVC-peak

\section{REFERENCES}

Alfreider, M., and Mühlegger, S. (2010). Konstruktion einer WildwarnerMessanlage. Diploma thesis, Höhere technische Bundeslehranstalt Jenbach.

Allen, R. E., and McCullough, D. R. (1976). Deer-car accidents in southern Michigan. J. Wildl. Manage. 40, 317-325. doi: 10.2307/ 3800431

Almkvist, B., André, T., Ekblom, S., and Rempler, S. A. (1980). Slutrapport Viltolycksprojekt. Swedish National Road Administration, TU146:1980-05. Borlänge.

Armstrong, J. J. (1992). An Evaluation of the Effectiveness of Swareflex Deer Reflectors. Downsview, CA: Ontario Ministry of Transportation. 18.

Ashley, E. P., and Robinson, J. T. (1996). Road mortality of amphibians, reptiles and other wildlife on the Long Point Causeway, Lake Erie, Ontario. Can. Field Nat. 110, 403-412.

Aspinall, I. (1994). Evaluation of Wildlife Warning Reflectors. Kew Victoria: VicRoads. 39.

Barlow, C. (1997). "Performance evaluation of wildlife reflectors in British Columbia," in Proceedings of the Second Roads, Rails and the Environment Workshop, eds A. P. Clevenger, K. Wells, and B. C. Revelstoke (Victoria, BC), 62-67.

Beauchamp, D. (1970). Deer Mirror Evaluation. W-51-R-15. California Department of Fish and Game. California. 8.

Beben, D. (2012). Crossings for animals - an effective method of wild fauna conservation. J. Environ. Eng. Landsc. 20, 86-96. doi: $10.3846 / 16486897.2012 .662753$

Bertwistle, J. (2009). An Assessment of Strieter Lite Reflectors. Jasper Alberta, AB. 9.

Bíl, M., Andrášik, R., and Janoška, Z. (2013). Identification of hazardous road locations of traffic accidents by means of kernel density estimation and cluster significance evaluation. Acct. Anal. Prev. 55, 265-273. doi: 10.1016/j.aap.2013.03.003

Binetruy, L., and Kenny, B. (2005). Animal Collision Countermeasures on rural Alberta Highways. Calgaray, AB: EBA Engineering Consultans Ltd. 24. seasons, are recommended for further studies testing the effectiveness of modern WWR.

\section{AUTHOR CONTRIBUTIONS}

AB: Idea for this publication, Literature Survey, Data Collection, Data Analyses, Statistics, Writing the manuscript; PA: Statistics, comments on the manuscript; TV: Project idea, Organization of funding, comments on the manuscript.

\section{ACKNOWLEDGMENTS}

We gratefully thank T. Lübbe and A. Seiler for providing helpful comments on the manuscript. Moreover, we like to thank Kathleen Regan, US, for comments on the manuscript. We further like to thank all the diligent librarians, who made a real effort to find lost publications. Funding was provided by the German insurers (GDV). We acknowledge support by the German Research Foundation and the Open Access Publication Funds of the Göttingen University.

\section{SUPPLEMENTARY MATERIAL}

The Supplementary Material for this article can be found online at: https://www.frontiersin.org/articles/10.3389/fevo. 2018.00037/full\#supplementary-material

Borenstein, M., Hedges, L. V., Higgins, J. P. T., and Rothstein, H. R. (eds.). (2009). "Effect sizes based on means," in Introduction to Meta-Analysis (Chichester: John Wiley \& Sons, Ltd.). doi: 10.1002/9780470743386.fmatter

Boyd, R. J. (1966). Deer mirrors. Do they work? Outdoor Facts 6, 44-45.

Brieger, F., Hagen, R., Kröschel, M., Hartig, F., Petersen, I., Ortmann, S., et al. (2017a). Do roe deer react to wildlife warning reflectors? A test combining a controlled experiment with field observations. Eur. J. Wildlife Res. 63, 72. doi: 10.1007/s10344-017-1130-5

Brieger, F., Hagen, R., Vetter, D., Dormann, C. F., and Storch, I. (2016). Effectiveness of light-reflecting devices: a systematic reanalysis of animal-vehicle collision data. Accid. Anal. Prev. 97, 242-260. doi: 10.1016/j.aap.2016.08.030

Brieger, F., Kämmerle, J.-L., Martschuk, N., Ortmann, S., and Hagen, R. (2017b). No evidence for a "warning effect" of blue light in roe deer. Wildlife Biol. 17. doi: 10.2981/wlb.00331

Bruinderink, G., and Hazebroek, E. (1996). Ungulate traffic collisions in Europe. Conserv. Biol. 10, 1059-1067. doi: 10.1046/j.1523-1739.1996.10041059.x

Carroll, J., Murphy, C. J., Neitz, M., Hoeve, J. N., and Neitz, J. (2001). Photopigment basis for dichromatic color vision in the horse. J. Vis. 1, 80-87. doi: $10.1167 / 1.2 .2$

Christensen, K. (2016). Evaluation of Strieter-Lite Wild Animal Highway Warning Reflector System TM on Reducing Vehicle-Animal Collisions. Montana Department of Transportation. 9.

Clarke, G. P., White, P. C. L., and Harris, S. (1998). Effects of roads on badger (Meles meles) populations in south-west England. Biol. Conserv. 86, 117-124. doi: 10.1016/S0006-3207(98)00018-4

Colino-Rabanal, V. J., Langen, T. A., Peris, S. J., and Lizana, M. (2018). Ungulate: vehicle collision rates are associated with the phase of the moon. Biodivers Conserv. 27, 681-694. doi: 10.1007/s10531-0171458-x

Compare, D. L., Sturaro, E., Cocca, G., and Ramanzin, M. (2007). An analysis of roe deer (Capreolus capreolus) traffic collisions in the Belluno province, eastern Italian Alps. Italian J. Anim. Sci. 6, 848-850. doi: 10.4081/ijas.2007.1s.848 
Cottrell, B. H. (2003). Evaluation of Deer Warning Reflectors in Virginia. Technical Assistance Report. Virginia Transportation Research Council in cooperation with US Department of Transportation and Federal Highway Administration. VTRC. 21.

Dalton, L. B., and Stranger, M. C. (1990). Effectiveness of Swareflex Reflectors at Reducing Mule Deer-Vehicle Collisions. Price, UT: Utah Division of Wildlife Resources. 7.

D’Angelo, G., D’Angelo, J. G., Gallagher, G. R., Osborn, D. A., Miller, and Warren, R. J. (2006). Evaluation of wildlife warning reflectors for altering white-tailed deer behavior along roadways. Wildlife Soc. B. 34, 1175-1183. doi: 10.2193/ 0091-7648(2006)34[1175:EOWWRF]2.0.CO;2

D'Angelo, G., and van der Ree, R. (2015). "Use of reflectors and auditory deterrents to prevent wildlife-vehicle collisions," in Handbook of Road Ecology, eds R. van der Ree, D. J. Smith, and C. Grilo (Chichester: John Wiley \& Sons, Ltd). 213-218.

De'ath, G., and Fabricius, K. E. (2000). Classification and regression trees: a powerful yet simple technique for ecological data analysis. Ecology 81, 3178-3192. doi: 10.1890/0012-9658(2000)081[3178:CARTAP]2.0.CO;2

DeNicola, A. J., VerCauteren, K. C., Curtis, P. D., and Hyngstrom, S. E. (2000). Managing White-Tailed Deer in Suburban Environments. Ithaca, NY: Cornell Cooperative Extension.

Ekblom, S. (1979). Undersökning av viltspeglars effect. Viltolycksprojektet (VIOL). Rapport nr 30. Stockholm: Statens Vägverk. 14.

Elith, J., Leathwick, J. R., and Hastie, T. (2008). A working guide to boosted regression trees. J. Anim. Ecol. 77, 802-813. doi: $10.1111 / j .1365-2656.2008 .01390 . x$

Elliot, A. J., Maier, M. A., Moller, A. C., Friedman, R., and Meinhardt, J. (2007). Color and psychological functioning: the effect of red on performance attainment. J. Exp. Psychol. Gen. 136, 154-168. doi: 10.1037/0096-3445.136.1.154

Elmeros, M., Winbladh, J. K., Andersen, P. N., Madsen, A. B., and Christensen, J. T. (2011). Effectiveness of odour repellents on red deer (Cervus elaphus) and roe deer (Capreolus capreolus): a field test. Euro J. Wildlife Res. 57, 1223-1226. doi: 10.1007/s10344-011-0517-y

Finder, R. A., Roseberry, J. L., and Woolf, A. (1999). Site and landscape conditions at white-tailed deer/vehicle collision locations in Illinois. Landscape Urban Plan. 44, 77-85. doi: 10.1016/S0169-2046(99)00006-7

Fjeld, G., and Antonsen, K. (1999). Viltreflektorers Virkning på Elgens Kryssing av vei. Master thesis, Høgskolen i Hedmark, Evenstad. 30.

Ford, S. G., and Villa, S. L. (1993). Reflector Use and the Effect They Have on the Number of Mule Deer Killed on California Highways: Final Report, Sacramento, CA: California Department of Transportation. 12.

Forkman, B., Boissy, A., Meunier-Salaün, M. C., Canali, E., and Jones, R. B. (2007). A critical review of fear tests used on cattle, pigs, sheep, poultry and horses. Physiol. Behav. 92, 340-374. doi: 10.1016/j.physbeh.2007.03.016

Fox, J. (2015). Applied Regression Analysis and Generalized Linear Models. Thousand Oaks, CA: Sage Publications.

Fryxell, J. M., Hussell, D. J. T., Lambert, A. B., and Smith, P. C. (1991). Time lags and population fluctuations in white-tailed deer. J. Wildlife Manage. 3, 377-385.

Fryxell, J. M., Packer, C., McCann, K., Solberg, E. J., and Sæther, B.E. (2010). Resource management cycles and the sustainability of harvested wildlife populations. Science 328, 903-906. doi: 10.1126/science. 1185802

Garver, J. (1976). Report on 1974-1975 roadside mirror study along Illinois Route 148 in Crab Orchard Refuge. Jonesbro, IL: Illinois Department of Conservation.

Gilbert, J. R. (1982). Evaluation of Deer Mirrors for Reducing Deer-Vehicle Collisions. Final Report. Springfield, VA: Federal Highway Administration. 14.

Gladfelter, L. (1984). Effect of Wildlife Highway Warning Reflectors on Deer-Vehicle Accidents. Project HR-210, Boone, IO: Iowa Highway Research Board. 11.

Goldstein, K. (1942). Some experimental observations concerning the influence of colors on the function of the organism. Am. J. Phys. Med. Rehab. 21, 147-151.

Gordon, D. F. (1969). Deer mirror- a clearer picture. Outdoor Facts 6, 77-79.

Green, R. H. (1979). Sampling Design and Statistical Methods for Environmental Biologists. New York, NY; Chichester; Brisbane; Toronto: John Wiley \& Sons.

Grenier, R. H. (2002). A Study of the Effectiveness of Strieter-Lite ${ }^{\circledR}$ Wild Animal Highway Warning Reflector Systems. Commissioned report for Strieter Corporation. 19.
Griffis, J. L. (1984).Effects of Swareflex Wildlife Highway Warning Reflectors on Behavior and Mortality of White-Tailed Deer. Master thesis, Southern Illinois University at Carbondale, USA. 71.

Gulen, S., McCabe, G., Rosenthal, I., Wolfe, S. E., and Anderson, V. L. (2006). Evaluation of Wildlife Reflectors in Reducing Vehicle Deer Collisions on Indiana Interstate 80/90. FHWA/IN/JTRP-2006/18. West Lafayette, IN: Indiana Department of Transportation and the U.S. Department of Transportation.

Gunson, K. E., Mountrakis, G., and Quackenbush, L. J. (2011). Spatial wildlifevehicle collision models: a review of current work and its application to transportation mitigation projects. J. Environ. Manage. 92, 1074-1082. doi: 10.1016/j.jenvman.2010.11.027

Hanggi, E. B., Ingersoll, J. F., and Waggoner, T. L. (2007). Color vision in horses (Equus caballus): deficiencies identified using a pseudoisochromatic plate test. J. Comp. Psychol. 121, 65-72. doi: 10.1037/0735-7036.121.1.65

Hedges, L. V., Gurevitch, J., and Curtis, P. S. (1999). The meta-analysis of response ratios in experimental ecology. Ecology 80, 1150-1156.

Hesse, G., and Rea, R. V. (2016). Quantifying Wildlife Vehicle Collision Underreporting on Northern British Columbia Highways (2004-2013): Unpublished Report Prepared for the BC Ministry of Transportation and Infrastructure. 53.

Hester, R. A. (1991). Evaluation of Roadside Reflectors in Preventing Deer-Vehicle Collisions at Bruce Nuclear Power Development. Report No. CPS-07017-0002. Ontario Hydro. Environmental Prot. Dept.

Hildebrand, E., and Hodgson, K. (1995). "Effectiveness of optical fences in reducing vehicle-deer collisions in new brunswick," in Proceedings of the Canadian Multidisciplinary Road Safety Conference IX (Montreal, QC). 131-144.

Hothorn, T., Müller, J., Held, L., Möst, L., and Mysterud, A. (2015). Temporal patterns of deer-vehicle collisions consistent with deer activity pattern and density increase but not general accident risk. Accid. Anal Prev. 81, 143-152. doi: 10.1016/j.aap.2015.04.037

Howe, S. (1967). Deer mirrors save deer... and cars. Maine Fish Game 29-30.

Hubbard, M. W., Danielson, B. J., and Schmitz, R. A. (2000). Factors influencing the location of deer-vehicle accidents in Iowa. J. Wildlife Manage. 64, 707-713. doi: $10.2307 / 3802740$

Huijser, M. P., Kociolek, A., McGowen, P. T., Hardy, A., Clevenger, A. P., and Ament, R. J. (2007a). Wildlife-vehicle Collisions and Crossing Mitigation Measures: a Toolbox for the Montana Department of Transportation. Helena, MT: Montana Department of Transportation.

Huijser, M. P., and Kociolek, A. V. (2008). Wildlife-vehicle Collision and Crossing Mitigation Measures: a Literature Review for Blaine County, Idaho. Bozeman, MT: Western Transportation Institute; Montana State University.

Huijser, M. P., McGowen, P. T., Fuller, J., Hardy, A., and Kociolek, A. (2007b). Wildlife-Vehicle Collision Reduction Study: Report to Congress. No. FHWAHRT-08-034. 251.

Ingebrigtsen, D. K., and Ludwig, J. R. (1986). Effectiveness of Swareflex Wildlife Warning Reflectors in reducing Deer-Vehicle Collisions in Minnesota. St. Paul, $\mathrm{MN}$ : Department of Natural Resources.

Iuell, B., Bekker, H. G. J., Cuperus, R., Dufek, J., Fry, G., Hicks, C., et al. (2003). "Wildlife and traffic: a European handbook for identifying conflicts and designing solutions," in COST 341 Habitat Fragmentation due to Transportation Infrastructure.

Jacobs, G. H., Deegan, I. I., J. F., Neitz, J., Murphy, B. P., Miller, K. V., and Marchinton, R. L. (1994). Electrophysiological measurements of spectral mechanisms in the retinas of two cervids: white-tailed deer (Odocoileus virginianus) and fallow deer (Dama dama). J. Comp. Physiol. 174, 551-557.

Jacobs, G. H., Deegan, J. F., and Neitz, J. A. (1998). Photopigment basis for dichromatic color vision in cows, goats, and sheep. Vis. Neurosci. 15, 581-584.

Janssen, L., and Claus, K. (1996). Wildspiegels: Beheer van Wildspiegels. Vadamecum Natuurtechniek. Brüssel, BE: Ministerie van de Vlaamse Gemeenschap.

Jared, D. (2002). Evaluation of Wild Animal Highway Warning Reflectors. Office of Materials and Research; Georgia Department of Transportation. 10.

Johnson, D. (1981). Deer Reflectors Update. Newsletter Minn. Dept. Transport. District. 2, 1.

Johnson, P. M., Nolan, B., and Moore, B. (1993). The Use of Wildlife Reflectors as a Means of Reducing Kangaroo Road Deaths-the Proserpine Rock-Wallaby 
Experience. Brisbane, QLD: Queensland Department of Environment and Heritage. 18.

Kämmerle, J.-L., Brieger, F., Kröschel, M., Hagen, R., Storch, I., and Suchant, R. (2017). Temporal patterns in road crossing behaviour in roe deer (Capreolus capreolus) at sites with wildlife warning reflectors. PLOS ONE 12:e0184761. doi: 10.1371/journal.pone.0184761

Kofler, H. (1984). Aufstellung von Wildwarnreflektoren. Wildbiolog. Ges. München. 45, 16-17.

Konings, P. (1986). Een Onderzoek Naar de Werking en Effectiviteit van Wildspiegels Voor Dassen. Arnhem, NL: Studentenverslag Rijksinstituut voor Naturbeheer.

Kruidering, A. M., Veenbaas, G., Kleijberg, R., Koot, G., Rosloot, Y., and van Jaarsveld, E. (2005). Leidraad faunavoorzieningen bij wegen. Delft: Rijkswaterstaat.

Ladstätter, K. (1974). Wildwarnreflektoren. Der Anblick 29, 378.

Langbein, J., Putman, R., Pokorny, B., Apollonio, M., and Andersen, R. (2011). "Traffic collisions involving deer and other ungulates in Europe and available measures for mitigation," in Ungulate Management in Europe: Problems and Practices, eds R. Putman, M. Apollonio and R. Andersen (Cambridge: Cambridge University Press), 215-259.

Lavsund, S., and Sandegren, F. (1991). Moose-vehicle relations in Sweden. Alces $27,118-126$

Lehtimaki, R. (1979). Elk Mirrors and Traffic. Deer and Traffic. Ministry of Agriculture and Forestry. 22.

Libjå, L. E., and Gundersen, M. (2001). Viltreflektorers Virkning på Elgens Kryssing av Veg. Master thesis, Høgskolen i Hedmark, Evenstad. 24.

Lien Aune, L. (2004). Viltreflektorers Virkning på Elgens Kryssing av vei. Master thesis, Høgskolen i Hedmark, Evenstad. 30.

Lück, F. W. (1977). Untersuchung an einer Swareflex-Wildwarnreflektoranlage im Reinhardswald. Diploma thesis, University of Göttingen, Germany. 101.

Madsen, A. B., Fyhn, H. W., and Prang, A. (1998). Traffic Killed Animals in Landscape Ecological Planning and Research. Trafikdrebte dyr $i$ Landskabsøkologisk Planlagning og Forskning. DMU Rapport 228. Århus. 43.

Madsen, A. B., Strandgaard, H., and Prang, A. (2002). Factors causing traffic killings of roe deer Capreolus capreolus in Denmark. Wildlife Biol. 8, 55-61.

Mah, L. (1989). Wildlife Warning Reflectors. Report No. ABTR/RD-89/08. Alberta Transportation and Utilities. 13.

Malo, J. E., Suarez, F., and Diez, A. (2004). Can we mitigate animalvehicle accidents using predictive models? J. Appl. Ecol. 41, 701-710. doi: 10.1111/j.0021-8901.2004.00929.x

Martschuk, N. (2014). Wirkung von Licht Unterschiedlichen Spektralbereichs auf Rehe (Capreolus capreolus): Ein Beitrag zur Erforschung der Effektivität von Wildwarnreflektoren. Master thesis, Albert-Ludwigs-University Freiburg, Germany. 54.

McLain, P. D. (1964). The story of the deer mirrors on the parkway. New Jers Outdoors 15, 13-18.

McShea, W., Stewart, C., Kearns, L., Licciol, S., and Kocka, D. (2008). Factors affecting autumn deer-vehicle collisions in a rural Virginia county. Hum. Wildl. Confl. 2, 110-121. Available online at: http://www.jstor.org/stable/24875111

Morrison, M. L., Block, W. M., Strickland, M. D., Collier, B. A., and Peterson, M. J. (2008). Wildlife Study Design. New York, NY: Springer Science \& Business Media.

Müller, S. (1977). Protection des Routes contre le Gibier: Surfaces Reflechissantes. Rapport intermédiaire No. 3. Berne. 26.

Mysterud, A., Langvatn, R., and Stenseth, N. C. (2004). Patterns of reproductive effort in male ungulates. J. Zool. 264, 209-215. doi: $10.1017 /$ S0952836904005618

Mysterud, A., Larsen, P. K., Ims, R. A., and Østbye, E. (1999a). Habitat selection by roe deer and sheep: does habitat ranking reflect resource availability? Can. J. Zool. 77, 776-783.

Mysterud, A., Lian, L. B., and Hjermann, D. Ø. (1999b). Scale-dependent trade-offs in foraging by European roe deer (Capreolus capreolus) during winter. Can. J. Zool. 77, 1486-1493.

Nettels, K. (1965). Mirrors to reduce deer-auto collisions. Outdoor Indiana 8, 22-25.

Nielsen, C. K., Anderson, R. G., and Grund, M. D. (2003). Landscape influences on deer-vehicle accident areas in an urban environment. J Wildlife Manage. 67, 46-51. doi: $10.2307 / 3803060$
Norman, P. C. (2001). Reducing Deer-Vehicle Collisions by the Use of Reflectors: A Summary of Current Research and Literature. Howard County Department of Recreation and Parks. 8.

O'Rourke, S. (1990). Report on Effectiveness of 'Swareflex Wildlife Warning Reflectors' After 9 Month Trial on State Highway 18. North of Coonamble, NSW.

Olbrich, P. (1984). Untersuchung der wirksamkeit von wildwarnreflektoren und der eignung von wilddurchlässen. Z. Jagdwiss. 30, 101-116. doi: 10.1007/BF02312729

Ossinger, M., and Schafer, J. A. (1992). Discovery Bay Deer Reflector Study: Progress Report for May 1992. Washington State Department of Transportation. 7.

Pafko, F., and Kovach, B. (1996). "Experience with deer reflectors," in Minnesota Experience with Deer Reflectors (Minneapolis: Minnesota Department of Transportation), 7.

Paxson, R. (1981). Flashing Lights Seem to Save Lives of Deer. Des Moines Sunday Register.

Pepper, H. W. (1999). Road Traffic Accidents and Deer Reflectors: a Comparative Trial of the Effectiveness of Standard Red and New Blue/Green Roadside Reflectors at Preventing Motor Vehicle and Wild Deer Collisions. Internal report on Project 257. Forestry Commission, Forest Research, London.

Pepper, H. W., Chadwick, A. H., and Packer, J. J. (1998). Deer Reflectors and Road Traffic Accidents through Forestry Commission Forests: A Review of Traffic Accident Records of Roads where Deer Warning Reflectors have Been Installed. Appendix to contract report VC 0317. Ministry of Agriculture Fisheries and Foods, London.

Pluntke, D. (2014). Halt bei Blau ist Schlau: Auswertung der Wildunfallzahlen im Landkreis Oldenburg sowie Rückschlüsse auf die Wirksamkeit Blauer Wildwarnreflektoren als Präventionsmaßnahme. Bachelor thesis, Leibniz University Hannover; University of Veterinary Medicine, Hannover, Germany. 31.

Pürstl, A. (2006). Tierärztliches Gutachten zum Farbsehvermögen von Rot- und Rehwild. Vienna: Tierambulanz Türkenschanzplatz. 7.

Queal, L. M. (1968). Effectiveness of Roadside Mirrors in Controlling Deer-Car Accidents. Research and Development Report No. 137. Michigan Department of Conservation. 9.

R Core Team (2018). R: A Language and Environment for Statistical Computing. Vienna: R Foundation for Statistical Computing. Available online at: https:// www.R-project.org/

Ramp, D., and Croft, D. B. (2006). Do wildlife warning reflectors elicit aversion in captive macropods? Wildl Res. 33, 583-590. doi: 10.1071/WR05115

Reeve, A. F., and Anderson, S. H. (1993). Ineffectiveness of Swareflex reflectors at reducing deer-vehicle collisions. Wildlife Soc. B. 21, 127-132.

Riginos, C., Graham, M. W., Davis, M. J., Johnson, A. B., May, A. B., Ryer, K. J., et al. (2018). Wildlife warning reflectors and white canvas reduce deer-vehicle collisions and risky road-crossing behavior. Wildl. Soc. Bull. 42, 119-130. doi: $10.1002 / w s b .862$

Riginos, C., Graham, M. W., Davis, M., Smith, C., and Johnson, A. (2015). Effects of Wildlife Warning Reflectors ("Deer Delineators") on Wildlife-Vehicle Collisions in Central Wyoming. FHWA-WY-15/03F. Jackson, WY: Teton Research Institute. 93.

Roedenbeck, I. A. E. (2007). Landscape-Scale Effects of Roads on Wildlife. Ph.D. thesis, University of Giessen. 157.

Rogers, E., and Premo, D. (2004). An Ecological Landscape Study of Deer-Vehicle Collisions in Kent County, Michigan. Report for the Michigan State Police, Office of Highway Safety and Planning. White Water Associates, Inc, Amasa, MI. 56.

Rowden, P., Steinhardt, D., and Sheehan, M. (2008). Road crashes involving animals in Australia. Accident Anal. Prev. 40, 1865-1871. doi: 10.1016/j.aap.2008.08.002

Rudelstorfer, K., and Schwab, K. (1975). Optische Einrichtungen im Dienste der Verkehrssicherheit. Innsbruck: University of Innsbruck. 57.

Rutberg, A. T., and Naugle, R. E. (2008). Deer-vehicle collision trends at a suburban immunocontraception site. Hum. Wildlife Conflicts 2, 60-67.

Schafer, J. A., Carr, W. P., and Penland, S. (1985). Effectiveness of wildlife warning reflectors in reducing deer-vehicle accidents in Washington State. J. Wildlife Manage. 19, 99-100.

Schapire, R. E. (2003). "The boosting approach to machine learning: an overview," in Nonlinear Estimation and Classification. Lecture Notes in Statistics, Vol. 171, eds D. D. Denison, M. H. Hansen, C. C. Holmes, 
B. Mallick, and B. Yu (New York, NY: Springer). doi: 10.1007/978-0-38721579-2_9

Schilderwerk Beutha (2017). Available online at: http://www.halbkreisreflektor.de/. (Accessed February 08, 2017).

Scholten, G., Loveland, G., and Spinazole, J. (1989). Effectiveness of Swareflex Reflectors. Idaho Department of Fish and Game.

Schulze, C., and Polster, J. U. (2017). "Wirkungsweise von Wildwarnern," in Forschung Straßenbau und Straßenverkehrstechnik 1127/2017, ed Bundesministerium für Verkehr und digitale Infrastruktur (Bremen), 96.

Schwabe, K. A., Schuhmann, P. W., Tonkovich, M. J., and Wu, E. (2000). An analysis of deer-vehicle collisions: the case of Ohio. Hum. Conflicts Wildl. Econ. Considerations. 91-103.

Sheridan, G. J. (1991). The Effectiveness of Swareflex and Wegu Brand Wildife Reflectors in Deterring Perameles gunnii (barred bandicoot) from Crossing a Section of Roadway. Ballarat, VIC: Ballarat University College. 23.

Sielecki, L. E. (2001). "Evaluating the effectiveness of wildlife accident mitigation installations with the wildlife accident reporting system (WARS) in British Columbia," in Proceedings of the 2001 International Conference on Ecology and Transportation, eds C. L. Irwin, P. Garrett, and K. P. McDermott (Raleigh, NC: Center for Transportation and the Environment; North Carolina University), 473-489.

Sivic, A., and Sielecki, L. E. (2001). Wildlife Warning Reflectors: Spectrometric Evaluation. Victoria, BC: Ministry of Transportation and Highways. 24.

Snow, N. P., Porter, W. F., and Williams, D. M. (2015). Underreporting of wildlifevehicle collisions does not hinder predictive models for large ungulates. Biol. Conserv. 181, 44-53. doi: 10.1016/j.biocon.2014.10.030

Steiner, W. (2011). "Wildtierbestände und Verkehr-Reduktion von verkehrsbedingtem Fallwild," in Forschungsarbeiten des Oesterreichischen Verkehrssicherheitsfonds 008, ed Bundesministerium Für Verkehr (Vienna: Innovation und Technologie), 139.

Steiner, W., Leisch, F., and Hackländer, K. (2014). A review on the temporal pattern of deer-vehicle accidents: impact of seasonal, diurnal and lunar effects in cervids. Accident Anal. Prev. 66, 168-181. doi: 10.1016/j.aap.2014.01.020

Stoner, D. (1925). The toll of the automobile. Science 61, 56-57. doi: $10.1126 /$ science.61.1568.56

Stoyan, D. (2000). Gutachten zur Wirksamkeit des AWIWA-Sytems. Gutachten. Institut für Stochastik; Technical University Bergakademie Freiberg. 2.

Szél, Á., Röhlich, P., Caffé, A. R., and van Veen, T. (1996). Distribution of cone photoreceptors in the mammalian retina. Microsc. Res Tech. 35, 445-462. doi: 10.1002/(SICI)1097-0029(19961215)35:6\&lt;445::AIDJEMT4\&gt;3.0.CO;2-H

Ujvari, M., Baagøe, H. J., and Madsen, A. B. (1998). Effectiveness of wildlife warning reflectors in reducing deer-vehicle collisions: a behavioral study. J. Wildl. Manage. 62, 1094-1099. doi: 10.2307/3802562

Underwood, A. J. (1997). Environmental decision-making and the precautionary principle: what does this principle mean in environmental sampling practice? Landsc. Urban Plan. 37, 137-146.

Underwood, A. J., and Chapman, M. G. (2003). Power, precaution, Type II error and sampling design in assessment of environmental impacts. J. Exp. Mar. Biol. Ecol. 296, 49-70. doi: 10.1016/S0022-0981(03) 00304-6

van den Berk, M. (2017). Proefprojekt. Available online at: http://www.itek.co.at/ fusszeile/vertriebspartner/proefproject/. (Accessed February 08, 2017).

van der Ree, R., Smith, D. J., and Grilo, C. (2015). Handbook of Road Ecology. Oxford, UK: John Wiley \& Sons. van Gelder, J. J. (1973). A quantitative approach to the mortality resulting from traffic in a population of Bufo bufo L. Oecologia 13, 93-95. doi: $10.1007 / \mathrm{BF} 00379622$

van Langevelde, F., and Jaarsma, C. F. (2009). Modeling the effect of traffic calming on local animal population persistence. Ecol Soc. 14, 39. doi: 10.5751/ES-03061-140239

VerCauteren, K., and Pipas, M. (2003). A review of color vision in white-tailed deer. Wildl. Soc. Bull. 31, 684-691. Available online at: http://www.jstor.org/ stable/3784587

Voß, H. (2007). Unfallhäufungen mit Wildunfällen: Modellversuch im Oberbergischen Kreis. Berlin: The German Insurers. 36.

Waring, G. H., Griffis, J. L., and Vaughn, M. E. (1991). White-tailed deer roadside behavior, wildlife warning reflectors, and highway mortality. Appl. Anim. Behav. Sci. 29, 215-223. doi: 10.1016/0168-1591(91)90249-W

Watson, M., and Klingel, J. (2000). Assessing Methods for Reducing Deer-Vehicle Accidents. Available online at: http://www.wildlife.state.nm.us/conservation/ habitat-handbook/ (Accessed February 08, 2017).

White, G. C. (1983). Sample Size Requirements for Reflector Study. Los Alamos: Los Alamos National Laboratory.

Williamson, L. (1980). Reflectors reduce deer-auto collisions. Outdoor News Bull. 34,2 .

Witzel, D. A., Springer, M. D., and Mollenhauer, H. H. (1978). Cone and rod photoreceptors in the white-tailed deer Odocoileus virginianus. Am. J. Vet. Res. 39, 699-701.

Woodard, T. N., Reed, D. F., and Pojar, T. M. (1973). Effectiveness of Swareflex Wildlife Warning Reflectors in Reducing Deer-Vehicle Accidents. Colorado Division of Wildlife. 5.

Woodham, D. (1991). Evaluation of Swareflex Wildlife Warning Reflectors. Denver, CO: Colorado Department of Transportation. 6.

Yokoyama, S., and Radlwimmer, F. B. (1998). The "five-sites" rule and the evolution of red and green color vision in mammals. Mol. Biol. Evol. 15, 560-567. doi: 10.1093/oxfordjournals.molbev.a025956

Zacks, J. L. (1985). An Investigation of Swareflex Wildlife Warning Reflectors. Okemos, MI: U.S. Department of Transportation; Federal Highway Administration and Michigan Department of Transportation. 41.

Zacks, J. L. (1986). Do White-tailed Deer Avoid Red? An Evaluation of the Premise Underlying the Design of Swareflex Wildlife Reflectors. Washington, DC: Transportation Research Record 1075; National Research Council. 35-36; 41-43.

Zacks, J. L., and Budde, W. (1983). Behavioral investigations of color vision in the white-tailed deer, Odocoileus virginianus. Invest. Ophthalmol. Visual Sci. Suppl. 24, 24-183.

Zuur, A. F., Ieno, E. N., and Elphick, C. S. (2010). A protocol for data exploration to avoid common statistical problems. Methods Ecol. Evol. 1, 3-14. doi: 10.1111/j.2041-210X.2009.00001.x

Conflict of Interest Statement: The authors declare that the research was conducted in the absence of any commercial or financial relationships that could be construed as a potential conflict of interest.

Copyright (c) 2018 Benten, Annighöfer and Vor. This is an open-access article distributed under the terms of the Creative Commons Attribution License (CC $B Y)$. The use, distribution or reproduction in other forums is permitted, provided the original author(s) and the copyright owner are credited and that the original publication in this journal is cited, in accordance with accepted academic practice. No use, distribution or reproduction is permitted which does not comply with these terms. 